\title{
Comparative Transcriptome Analysis of the Expression of Antioxidant and Immunity Genes in the Spleen of a Cyanidin 3-O-Glucoside-Treated Alzheimer's Mouse Model
}

\author{
Varun Jaiswal $^{1,+}\left(\mathbb{D}\right.$, Miey Park ${ }^{1,2,+}$ and Hae-Jeung Lee ${ }^{1,2, *(\mathbb{D}}$ \\ 1 Department of Food and Nutrition, College of BioNano Technology, Gachon University, \\ Seongnam-si 13120, Gyeonggi-do, Korea; computationalvarun@gmail.com (V.J.); mpark@gachon.ac.kr (M.P.) \\ 2 Institute for Aging and Clinical Nutrition Research, Gachon University, \\ Seongnam-si 13120, Gyeonggi-do, Korea \\ * Correspondence: skysea@gachon.ac.kr; Tel.: +82-31-750-5968; Fax: +82-31-724-4411 \\ + These authors contributed equally to this study.
}

check for

updates

Citation: Jaiswal, V.; Park, M.; Lee, H.-J. Comparative Transcriptome Analysis of the Expression of Antioxidant and Immunity Genes in the Spleen of a Cyanidin 3-O-Glucoside-Treated Alzheimer's Mouse Model. Antioxidants 2021, 10, 1435. https://doi.org/10.3390/ antiox10091435

Academic Editor: Stanley Omaye

Received: 20 July 2021

Accepted: 7 September 2021

Published: 9 September 2021

Publisher's Note: MDPI stays neutral with regard to jurisdictional claims in published maps and institutional affiliations.

Copyright: (c) 2021 by the authors. Licensee MDPI, Basel, Switzerland. This article is an open access article distributed under the terms and conditions of the Creative Commons Attribution (CC BY) license (https:// creativecommons.org/licenses/by/ $4.0 /)$.

\begin{abstract}
Cyanidin 3-O-glucoside (C3G) is a well-known antioxidant found as a dietary anthocyanin in different fruits and vegetables. It has protective and therapeutic effects on various diseases. It can reduce neuronal death from amyloid-beta $(A \beta)$-induced toxicity and promote the inhibition of $A \beta$ fibrillization. Antioxidant and immune modulation might play a critical role in the properties of C3G against Alzheimer's disease (AD) and other diseases. However, limited studies have been performed on the mechanism involved in the effect of C3G through transcriptome analysis. Thus, the objective of this study was to perform comparative transcriptome analysis of the spleen to determine gene expression profiles of wild-type mice (C57BL/6J Jms), an Alzheimer's mouse model (APPswe/PS1dE9 mice), and a C3G-treated Alzheimer's mouse model. Differentially expressed antioxidant, immune-related, and $\mathrm{AD}$ pathways genes were identified in the treated group. The validation of gene expression data via RT-PCR studies further supported the current findings. Six important antioxidant genes (S100a8, S100a9, Prdx2, Hp, Mpst, and Prx12a) and a high number of immune-related genes were found to be upregulated in the treatment groups, suggesting the possible antioxidant and immunomodulatory mechanisms of C3G, respectively. Further studies are strongly recommended to elucidate the precise role of these essential genes and optimize the therapeutic function of $\mathrm{C} 3 \mathrm{G}$ in $\mathrm{AD}$ and other disease conditions.
\end{abstract}

Keywords: cyanidin 3-O-glucoside; Alzheimer's disease; transcriptome; antioxidant; immune modulation; genes; mechanisms

\section{Introduction}

Cyanidin 3-O-glucoside (C3G) is an important dietary anthocyanin that is present in different fruits, vegetables, and grains. Studies are increasingly reporting that C3G has protective effects and therapeutic potential against diseases such as diabetes [1-3], obesity [4], cardiovascular disease [2,5], neurological diseases [6], asthma [7], atherosclerosis [8], Alzheimer's disease (AD) [6], and different types of cancer [9-13]. These multiple pharmacological properties of C3G might be primarily attributed to its antioxidant and immunomodulatory effects $[10,14-16]$. In the past, a few studies have investigated genes and elucidated the mechanism involved in the immunomodulation and antioxidant properties of C3G. Therefore, the current study was designed to investigate the effect of C3G on the whole-transcriptome expression of the spleen to discover important immune-modulating and antioxidant system genes using wild-type and AD mouse models.

In Korea, AD was reported to be the ninth leading cause of death [17], and deaths caused by $\mathrm{AD}$ are expected to increase [17]. AD is the sixth leading cause of death in the United States [18], with an estimated more than six million individuals diagnosed with AD 
in the age group of 65 years or above in 2021 [19]. The occurrence of $\mathrm{AD}$ in 2050 is expected to be double the current level [19]. C3G is protective against glutamate-induced neuronal cell death [20] and ischemia-induced neuronal cell death [21,22]. It can prevent ethanol neurotoxicity [23] and can protect against amyloid $\beta(\mathrm{A} \beta)$-induced cytotoxicity [23-25]. It can also promote the inhibition of $\mathrm{A} \beta(\mathrm{A} \beta 40, \mathrm{~A} \beta 1-42)$ fibrillization and protect neuronal cells from $A \beta 1-42, A \beta 40$, and $A \beta 25-35$ induced cytotoxicity [6,24-27]. In rats, $C 3 G$ can prevent the cognitive impairment induced by $A \beta$ [28]. The in vitro and in vivo protection of $C 3 G$ against neuronal cell death (other than $A \beta$-induced cell death) suggests its protective effect via other mechanisms in addition to the inhibition of $A \beta$ fibrillization [20-23]. Although antioxidant activity and immune modulation were observed following C3G administration in different studies, the molecular genetic mechanisms underlying its immune modulation in AD pathogenesis are not yet well-studied [29]. The spleen is one of the most important organs in the immune system. It mediates a wide range of immunological functions [30]. The spleen has also been used to study antioxidant activity in different organisms [31-34]; therefore, we conducted gene expression studies with spleens obtained from a mouse model of $\mathrm{AD}$ following C3G treatment to identify the important genes and mechanisms for immune modulation, antioxidant activity, and subsequent AD pathogenesis. Whole-transcriptome analysis via RNA-Seq data combined with computational analysis can provide insights into different biological mechanisms [35-41]. In this study, analysis of the entire transcriptome of the C3G-treated mouse model of AD compared with the untreated mouse model of $\mathrm{AD}$ and wild-type mice was used to identify differentially expressed genes (DEGs) and transcripts. These DEGs, involved in the clearance of reactive oxygen species, inflammation, immune response, and innate immunity, are expected to provide insight into the antioxidant and immunomodulatory mechanisms of C3G and its possible role in $\mathrm{AD}$ and other diseases [38].

\section{Materials and Methods}

\subsection{Materials and Animal Model}

The C3G (cyanidin-3-O-glucoside $\left(\mathrm{C}_{21} \mathrm{H}_{21} \mathrm{O}_{11}\right.$, Cat. No. CFN99740)) used in the study was purchased from ChemFaces (Wuhan, Hubei, China). Animals used in this study included wild-type mice (C57BL/6J Jms) purchased from Hamamatsu-shi, Shizuoka, Japan, grouped as Wt mice, and AD model mice (APPswe/PS1dE9 mice) purchased from the Jackson laboratory [42], designated as ADM mice. AD model mice treated with C3G were grouped as ADM mice+C3G. All animals used in the study were nine months old. They underwent two weeks of acclimatization before starting the experiment. Mice (3 mice in each group) were randomly selected without any bias. The C3G dose administered by oral gavage for the ADM mice+C $3 \mathrm{G}$ group was $30 \mathrm{mg} / \mathrm{kg} /$ day for 38 weeks. These mice were provided ad libitum access to food and water during this study. The dose and study period were decided according to similar studies that investigated the effect of C3G $[1,9,27,43]$. This animal study was conducted in accordance with guidelines stipulated by the Ministry of Food and Drug Safety for the Care and Use of Laboratory Animals. It was approved by the Institutional Animal Care and Use Committee of Eulji University School of Medicine (EUIACUC 20-13). All efforts were made to minimize the number and suffering of animals used in the study. Mice were anesthetized using $\mathrm{CO}_{2}$. Their spleens were removed for RNA extraction.

\subsection{RNA-Seq Library Preparation and Sequencing}

Spleen tissue samples were homogenized to extract total RNA using a TRIzol reagent (Thermo Fisher Scientific, Waltham, MA, USA)-based method. Total RNA (500 ng) was used to prepare the entire transcriptome sequencing library. The whole-transcriptome RNA was enriched by depleting ribosomal RNA (rRNA) to generate the whole-transcriptome sequencing library using MGIEasy RNA Directional Library Prep Kit (MGI) according to the manufacturer's instructions. The remaining RNA was fragmented at an elevated temperature. These cleaved RNA fragments were used to synthesize first-strand cDNA 
with reverse transcriptase and random primers. Strand specificity was achieved with RT directional buffer, followed by second-strand cDNA synthesis. These cDNA fragments contained an additional single A base and subsequent ligation of the adapter. Products were then purified and enriched with PCR to create the final cDNA library. The doublestranded cDNA library was quantified using a QauntiFluor ONE dsDNA System (Promega, Madison, WI, USA). It had $330 \mathrm{ng}$ in a total volume of $60 \mathrm{~mL}$ or less. The library was incubated at $37^{\circ} \mathrm{C}$ for $60 \mathrm{~min}$ and then digested at $37^{\circ} \mathrm{C}$ for $30 \mathrm{~min}$, followed by a cleanup of circularization product. The library was incubated at $30^{\circ} \mathrm{C}$ for $25 \mathrm{~min}$ using DNB enzyme to obtain a DNA nanoball (DNB). Finally, the library was quantified using a QauntiFluor ssDNA System (Promega). The prepared DNB was sequenced using an MGIseq system (MGI) with 150 bp paired-end reads.

\subsection{RNA-Seq Analysis of Assembly and Differential Expression of Genes}

Paired-end reads from all 9 samples were used for RNA-Seq data analysis of three different groups (NM, AM, and CAM) to assemble the whole transcriptome for comparative analysis. Quality control (QC) is important when initially selecting good-quality reads for further processing. AfterQC was used for $\mathrm{QC}$, which entailed filtering, trimming, and error removal [44]. Good-quality reads were obtained as the output from the QC step for all 9 samples. They were used for the alignment with the reference genome (GRCm38, the mouse reference genome assembly released by the Genome Reference Consortium) using HISAT2 [45]. Alignment files in Sequence Alignment Map (SAM) format were converted to BAM files through SAMtools [46] for further assembly. Finally, StringTie assembler [47] was used to assemble alignment files (BAM format). The assembler was used with the -e option, which required a combination of the output of all samples for further differential expression analysis using EdgeR [48] and DESeq2 [49]. Default statistical cutoff parameters for identifying DEGs (FDR $<0.1$ and minimum 2-fold change) were used in DESeq2.

\subsection{Function Enrichment of DEGs}

Differentially expressed genes (DEGs) were subjected to functional enrichment analysis using protein analysis through evolutionary relationship (PANTHER) [50] and AllEnricher [51]. PANTHER was used to perform enrichment analysis based on biological process, cellular component, molecular function, protein class, and pathway enrichment [50]. AllEnricher was used for functional interpretation based on gene ontology (GO) [52], Reactome [53], and visualization through a bubble plot. The latest libraries of these resources were downloaded and used for the analysis.

\subsection{Comparison of DEGs and Identification of Antioxidant and Immune Genes}

Comparison of the DEGs identified in differential expression analysis between Wt mice vs. ADM mice and ADM mice+C3G vs. ADM mice was performed using InteractiVenn [54] to identify the important genes that were up- or downregulated. DEGs from the comparison between ADM mice and ADM mice+C3G were used to identify antioxidant genes through the antioxidant protein database (AOD), which contains antioxidant proteins reported in the literature [55]. All antioxidant proteins reported in mice were collected from the AOD database and converted to gene ID with the help of g:Profiler [56]. Venn analysis was used again to identify the DEGs present in the collected gene IDs. The DEGs identified in the comparison between $\mathrm{ADM}$ mice and $\mathrm{ADM}$ mice $+\mathrm{C} 3 \mathrm{G}$ were also compared with immunerelated gene sets. Two gene sets (immune gene set 1 and immune genes set 2 ) were prepared for the comparison. Immune gene set-1 (ImmGS1) is composed of all immunity-related genes derived from the immunome database, which collects genes known to be directly involved in immune mechanisms reported in the literature [57]. Similarly, immune gene set 2 (ImmGS2) was prepared from genes reported in innateDB, which collects genes involved in innate immunity [57]. As genes in innateDB were obtained from human,; homologous genes were searched for in mice using g:Profiler [56]. Finally, all genes associated with innate immunity in mice were converted to gene accession numbers to create ImmGS2. 
Both gene sets (ImmGS1 and ImmGS2) were used for comparison with the DEGs to identify common genes in different comparisons via set analysis. InteractiVenn was used to perform set analysis to create a Venn diagram and prepare the list of common genes [54].

\subsection{Protein-Protein Interaction Network}

All DEGs from both comparisons were used to construct a protein-protein interaction network (PPIN) using STRING-version11.0 [58]. Lists of the DEGs from both comparisons (Wt mice vs. ADM mice and $\mathrm{ADM}$ mice+C3G vs. ADM mice) were used separately to construct two different PPINs. PPIN and KEGG network enrichment analyses were conducted using Mus musculus as the target organism in the server. The default settings were used in this study. Statistical parameters such as $p$-value for analysis were calculated and the results were extracted in tab-separated variables and PNG image formats.

\subsection{Quantitative Real-Time PCR ( $q$ RT-PCR) Assay to Validate the Expression of Important Genes}

DEGs that were up- or downregulated in both comparisons, Wt mice vs. ADM mice and $\mathrm{ADM}$ mice+C $3 \mathrm{G}$ vs. ADM mice (except the genes not expressed in samples belonging to more than one group), were selected for validation via RT-PCR. The gene sequences of all selected genes were obtained from Ensemble [59]. Primers were designed using the primer3web server. Primer sequences are provided in Table S1.

\section{Results}

3.1. Quality Control and Alignment of RNA-Seq Reads

A total of 212,745,311 reads were obtained from the RNA-Seq analysis of all nine samples, with an average of 23,638,367.8 reads per sample (Table 1). Preprocessing is the initial step of RNA-Seq analysis, mainly used for QC. A high percentage $(>95 \%)$ of good reads was obtained for all the samples, with an average of $96.4 \%$ (Table 1). Subsequently, a high percentage ( $>91 \%)$ of overall alignment with the mouse reference genome (GRCm38) was achieved, with an average of $92.9 \%$ for all the samples (Table 1 ).

Table 1. Preprocessing and alignment results of all nine samples.

\begin{tabular}{|c|c|c|c|c|c|}
\hline No. & Group & Sample ID & Number of Reads & $\begin{array}{l}\text { Number of Good } \\
\text { Reads (Percentage) }\end{array}$ & $\begin{array}{c}\text { Overall } \\
\text { Alignment Rate }\end{array}$ \\
\hline 1 & \multirow{3}{*}{ Wt mice } & VC1 & $21,622,102$ & $20,743,123(95.9 \%)$ & $93.51 \%$ \\
\hline 2 & & VC4 & $23,804,636$ & $22,983,122(96.5 \%)$ & $94.19 \%$ \\
\hline 3 & & VC6 & $25,529,616$ & $24,586,395(96.3 \%)$ & $94.10 \%$ \\
\hline 4 & \multirow{4}{*}{ ADM mice } & APP2 & $20,475,388$ & $19,700,219(96.2 \%)$ & $93.03 \%$ \\
\hline 5 & & $\mathrm{APP} 4$ & $20,315,569$ & $19,541,861(96.1 \%)$ & $91.00 \%$ \\
\hline 6 & & APP6 & $24,571,206$ & $23,772,655(96.7 \%)$ & $93.35 \%$ \\
\hline 7 & & C2 & $25,878,453$ & $25,060,447(96.8 \%)$ & $91.31 \%$ \\
\hline 8 & \multirow{2}{*}{$\mathrm{ADM}$ mice+C3G } & $\mathrm{C} 4$ & $25,609,508$ & $24,844,294(97.01 \%)$ & $93.06 \%$ \\
\hline 9 & & C6 & $24,938,833$ & $24,141,244(96.8 \%)$ & $92.61 \%$ \\
\hline 10 & All samples & & $\begin{array}{c}\text { Total: } 212,745,311 \\
\text { Average: } 23,638,367.8\end{array}$ & Total: $205,373,360$ & Mean: $92.906 \%$ \\
\hline
\end{tabular}

\subsection{Assembly and Differential Expression Analysis}

The whole transcriptome was built via the assembled reads obtained from the alignment files. The expression was determined in the form of fragments per kilobase of transcript per million mapped reads (FPKM). Read count and FPKM values were calculated for each assembled gene/transcript. Furthermore, the gene count of all nine samples was used in the differential-expression-related analyses as the preferred input. The preprocessed results are graphically presented as a read count bar plot, a distribution of transformed data plot, and a density plot of transformed data (Figure S1a). The first and second principal components were used for the PCA plot, which shows the difference between the groups in this study. The samples from the control group cluster in the right portion of the graph. 
The samples from the ADM group and the ADM +C3G groups cluster on the opposite side. The samples from the ADM group cluster above the ADM+C3G group (Figure S1a). Similar graphs were obtained from multidimensional scaling and t-SNE options [60] (Figure S1b). The differential expression analysis via DEseq2 revealed up- and downregulated genes among the different groups used in the study [61]. A comparison of the ADM mice with the Wt mice revealed the upregulation of 444 genes and the downregulation of 904 genes. The comparison of the ADM mice and the ADM mice+C3G revealed 487 upregulated genes and 53 downregulated genes (Table S2). The heat map, MA, and volcano plots of DEGs were derived from both the comparisons (Figures 1 and 2). The selected DEGs were further enriched and analyzed.

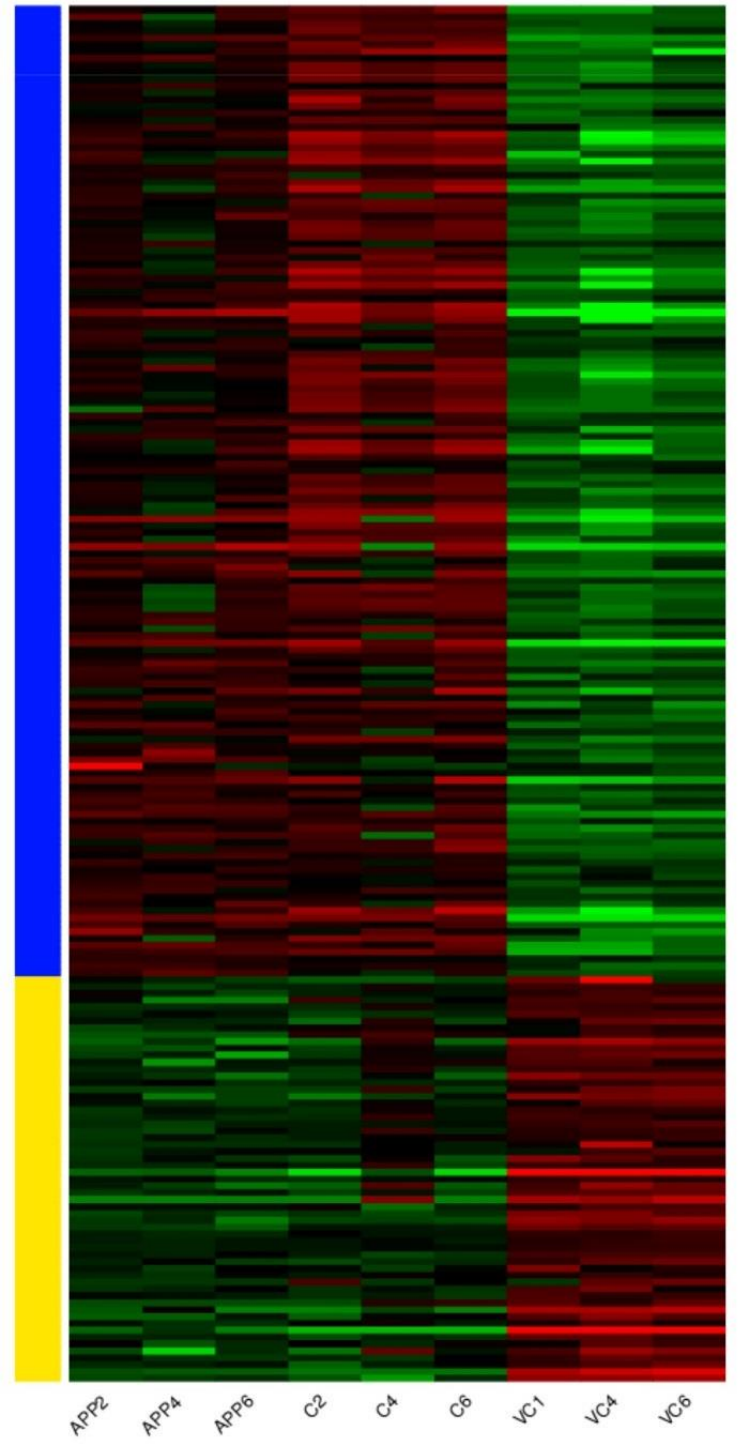

(A)

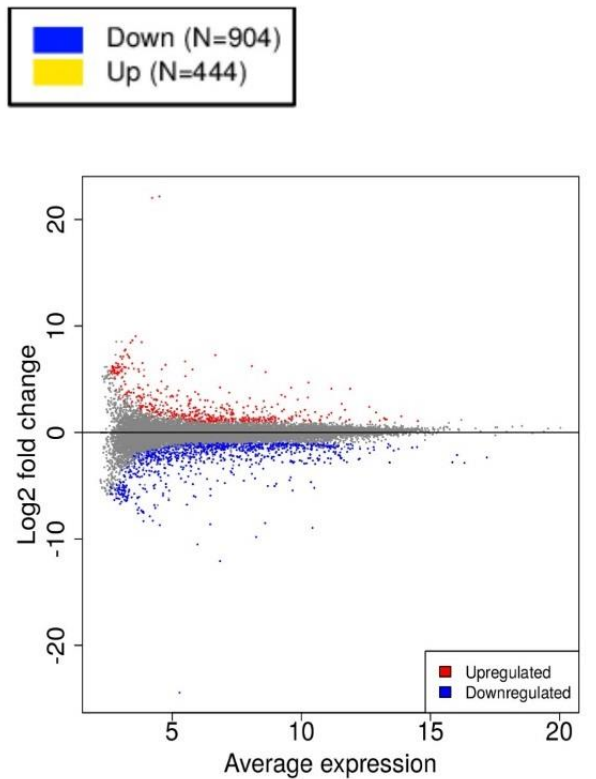

(B)

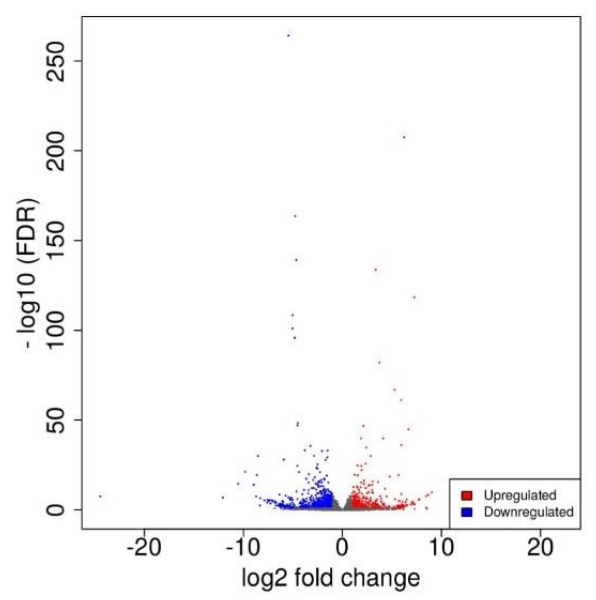

(C)

Figure 1. (A) Heatmap, (B) MA, and (C) volcano plots of differentially expressed genes (DEGs) in the comparison of Wt mice vs. ADM mice. 


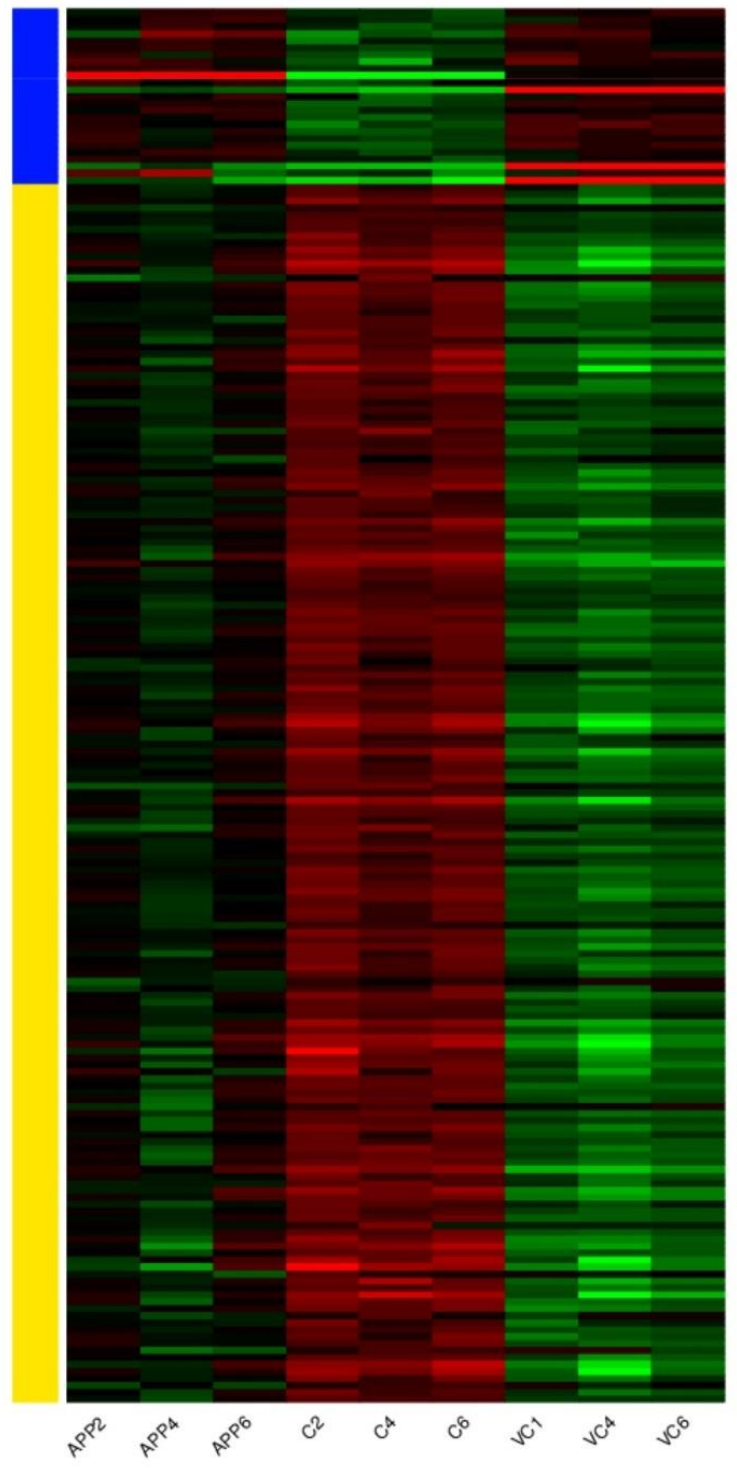

(A)

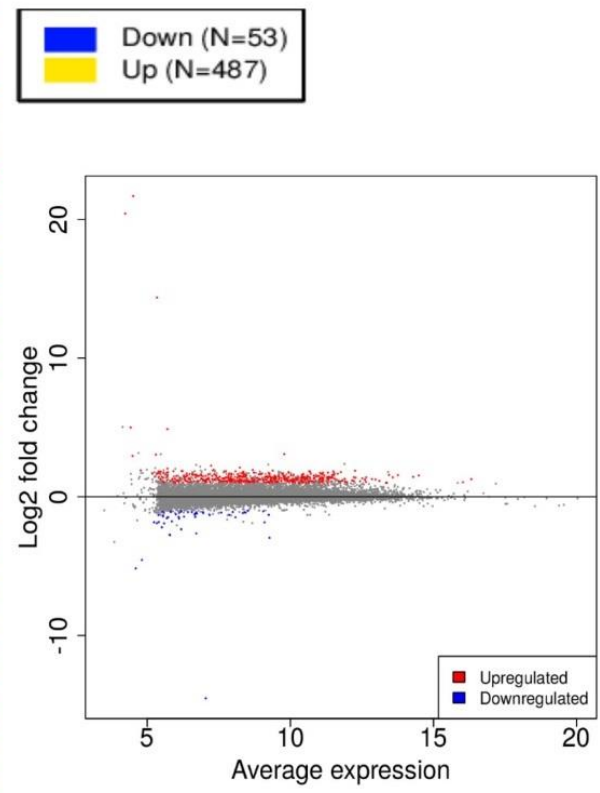

(B)

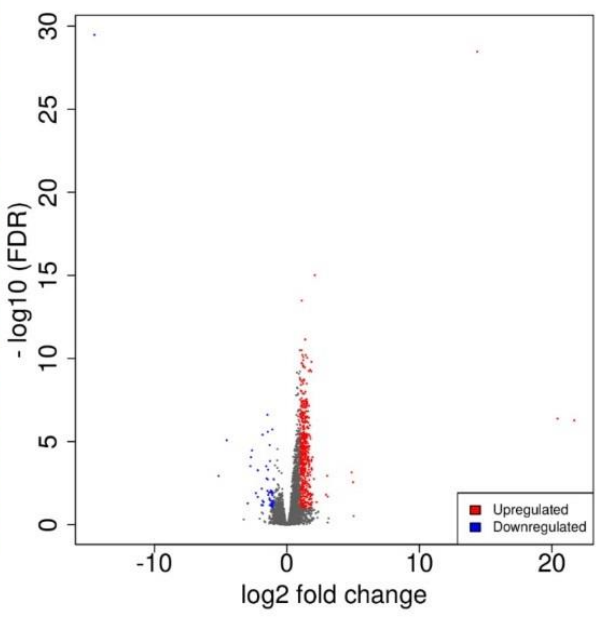

(C)

Figure 2. (A) Heatmap, (B) MA, and (C) volcano plots of differentially expressed genes (DEGs) in comparison of $\mathrm{ADM}$ mice $+\mathrm{C} 3 \mathrm{G}$ vs. ADM mice.

\subsection{Functional Enrichment Analysis of DEGs}

Enrichment analysis was performed according to the biological process, cellular component, molecular function, protein class, pathway, and reactome pathway analysis. The upregulated DEGs in the Wt mice, compared with those in the ADM mice, were enriched in 18 biological processes, 3 cellular components, 7 molecular functions, 18 protein classes, 31 pathways, and 337 reactome pathways (Table S2a-f and Figure S2a). The downregulated DEGs in the Wt mice, compared with the ADM mice, were enriched in 19 biological processes, 3 cellular components, 8 molecular functions, 22 protein classes, 80 pathways, and 334 reactome pathways (Table S3a-f and Figure S2b). Similarly, the upregulated DEGs in the ADM mice+C3G group, compared with the ADM mice, were enriched in 16 biological processes, 3 cellular components, 8 molecular functions, 20 protein classes, 55 pathways, and 116 reactome pathways (Table S4a-f and Figure S2c). The downregulated DEGs in the ADM mice+C3G group, compared with the ADM mice, were enriched in 10 biological processes, 3 cellular components, 4 molecular functions, 10 protein classes, and 9 pathways (Table S5a-e). 


\subsection{Identification of Common DEGs in Comparison}

Five genes (Slpi, Oas2, Gm15133, Ighv11-2, and Nnt) were found to be upregulated in both the Wt mice vs. ADM mice and the ADM mice+C3G vs. ADM mice comparisons (Table 2). Similarly, four genes (Cd209e, D630045J12Rik, Gm10260, and Igkv8-28) were found to be downregulated in both the Wt mice vs. ADM mice and the ADM mice+C3G vs. ADM mice comparisons. However, 253 and 6 DEGs showed opposite expression patterns, i.e., 253 DEGs were downregulated in the Wt mice vs. ADM mice and upregulated in the $\mathrm{ADM}$ mice+C3G vs. ADM mice comparisons, respectively, and vice versa (Figure $3 \mathrm{~A}$ ).

Table 2. Differentially expressed genes proposed to be important candidate in C3G -induced antioxidant and/or immune modulation activity.

\begin{tabular}{|c|c|c|c|c|c|}
\hline Sr. No. & Gene Name & $\begin{array}{l}\text { Differential } \\
\text { Expression }\end{array}$ & $\begin{array}{l}\text { Associated with } \\
\text { Immune Function }\end{array}$ & $\begin{array}{l}\text { Associated with } \\
\text { Antioxidant Activity }\end{array}$ & Associated with AD \\
\hline 1 & Slpi & \multirow{4}{*}{$\begin{array}{l}\text { Upregulated in } \\
\text { both the } \\
\text { comparisons }\end{array}$} & Yes & Yes & Yes \\
\hline 2 & Oas2 & & Yes & & \\
\hline 3 & Ighv11-2 & & Yes & & \\
\hline 4 & Nnt & & Yes & Yes & Yes \\
\hline 5 & S100a8 & \multirow{6}{*}{$\begin{array}{l}\text { Upregulated in } \\
\text { comparison II } \\
\text { (i.e., treatment } \\
\text { group) }\end{array}$} & Yes & Yes & Yes \\
\hline 6 & S100a9 & & Yes & Yes & Yes \\
\hline 7 & $\operatorname{Prd} 22$ & & Yes & Yes & Yes \\
\hline 8 & $\mathrm{Hp}$ & & Yes & Yes & Yes \\
\hline 9 & Mpst & & & Yes & Yes \\
\hline 10 & Prxl2a & & & Yes & \\
\hline
\end{tabular}

\subsection{Identification of DEGs with Antioxidant Activity}

Comparing the DEGs between the ADM mice+C3G and the ADM mice and the known antioxidant genes resulted in the identification of six antioxidant genes (S100a8, S100a9, Prdx2, Hp, Mpst, and Prx12a), which were upregulated in the C3G treatment group (Table 2). No antioxidant gene was downregulated in the ADM mice+C3G group (Figure 3B).

\subsection{Identification of DEGs with Immune-Related Function}

When the DEGs were analyzed for ImmGS1 (comprising the immune genes directly involved in immune-related processes), 28 genes and 1 gene were found to be upregulated and downregulated, respectively, in the ADM mice+C3G than in the ADM mice. When the DEGs were analyzed for ImmGS2 (innate immunity genes), 33 were upregulated and 1 gene was downregulated in the ADM mice $+\mathrm{C} 3 \mathrm{G}$ than in the ADM mice (Figure $3 \mathrm{C}$ ).

\subsection{PPIN Analysis}

Two separate protein-protein interaction networks, PPIN1 and PPIN2, were drawn from the DEGs identified in the ADM mice vs. Wt mice and the ADM mice+C3G vs. ADM mice comparisons, respectively (Figure S3a,b). A highly connected network was observed in both analyses. In PPN1, the total number of nodes was 839, with 3748 edges and an average node degree of 8.93, although the expected number of edges was only 1986 (Figure S3a and Table S6a). Similarly, in PPIN2, a total of 6429 edges were observed between 463 nodes, with an average node degree of 27.8 , although the expected number of edges was 1364 (Figure S3b and Table S6b). The PPI enrichment $p$-values were less than $1.0 \times 10^{-16}$ in both the PPIN1 and PPIN2 networks (Table S6a,b). 


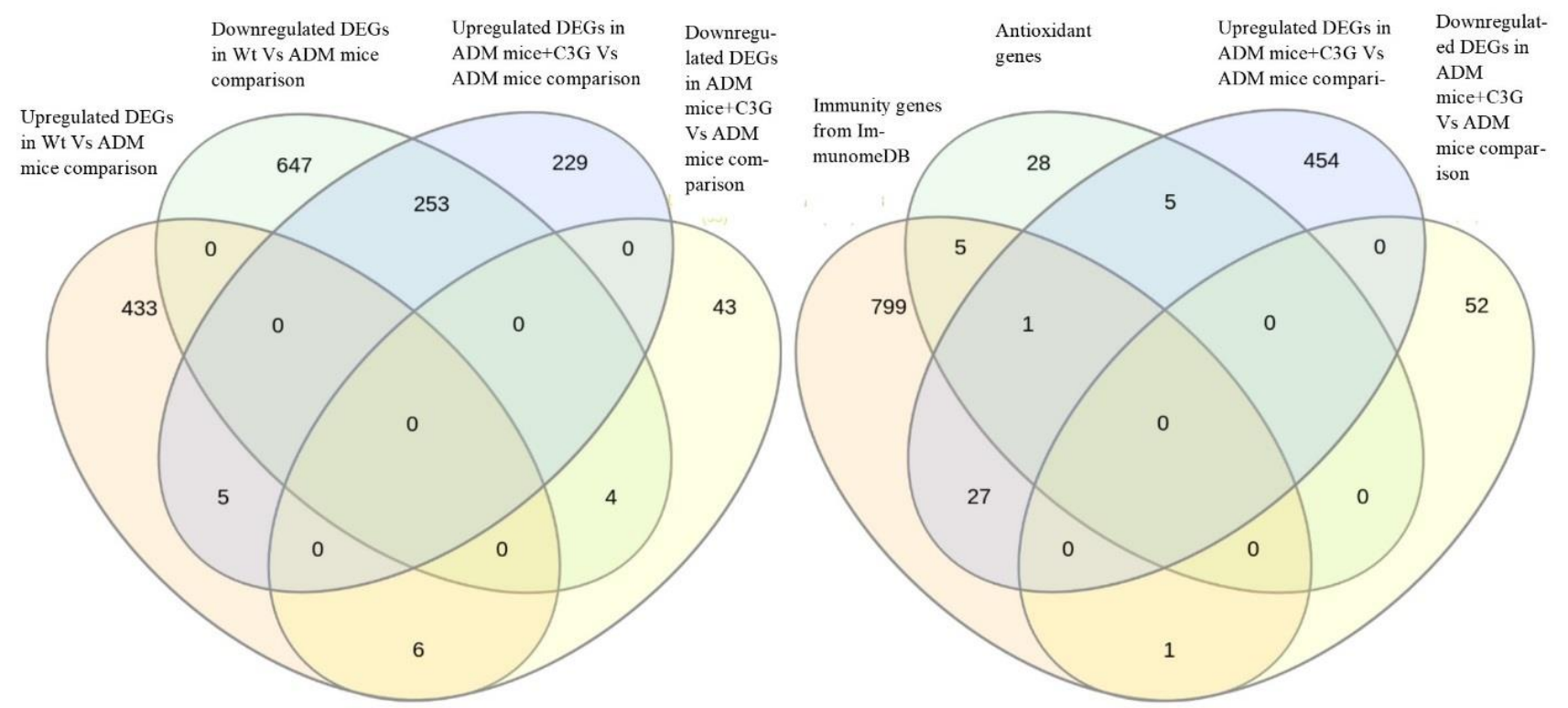

\section{(A)}

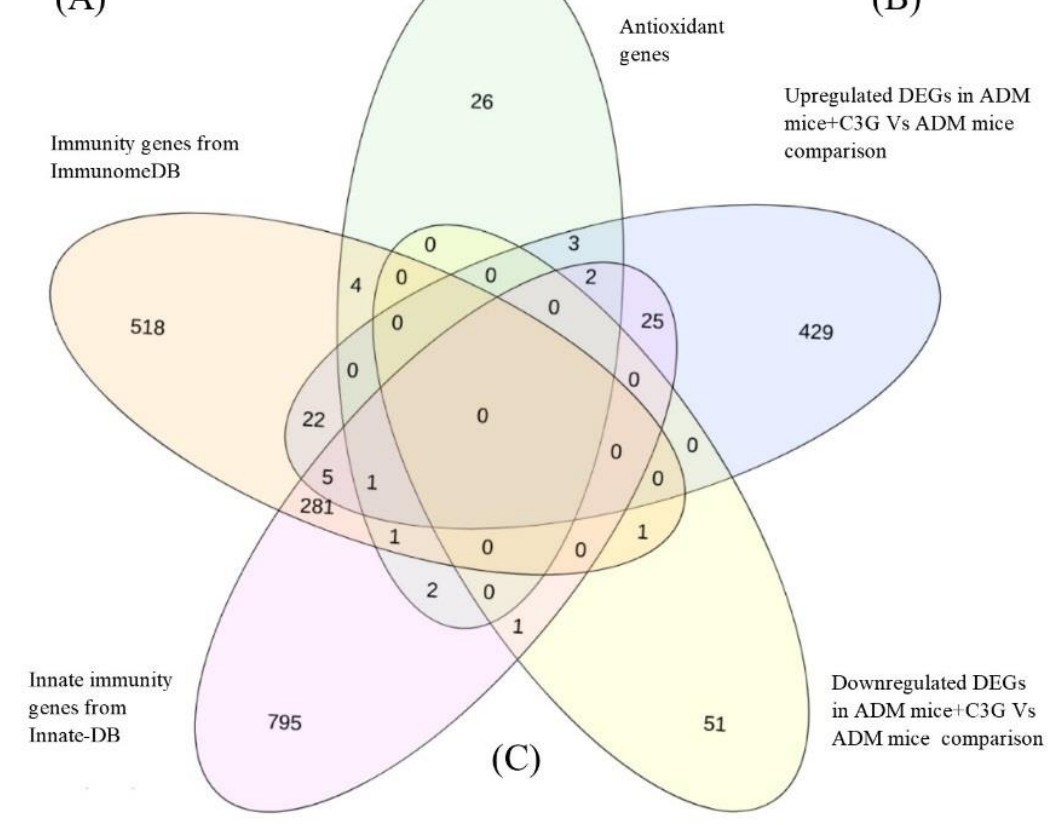

Figure 3. (A) Venn diagram of DEGs based on Wt mice vs. ADM mice and ADM mice+C3G vs. ADM mice comparisons. (B) Venn diagram of DEGs (Wt mice vs. ADM mice) overlapping with immunome database and genes associated with innate immunity from InnateDB. (C) Venn diagram between DEGs (ADM mice+C3G vs. ADM mice) with antioxidant, immunome database, and innate immune-related genes.

\section{8. qRT-PCR Assay}

The expressions of selected genes that were up- or downregulated in both comparisons, i.e., Wt mice vs. ADM mice and ADM mice+C3G vs. ADM mice in the RNA-Seq analysis, were validated using all nine samples via qRT-PCR assays. All the genes followed a similar expression pattern in each group (up- or downregulated in both comparisons) according to the RNA-Seq analysis (Figure 4). 


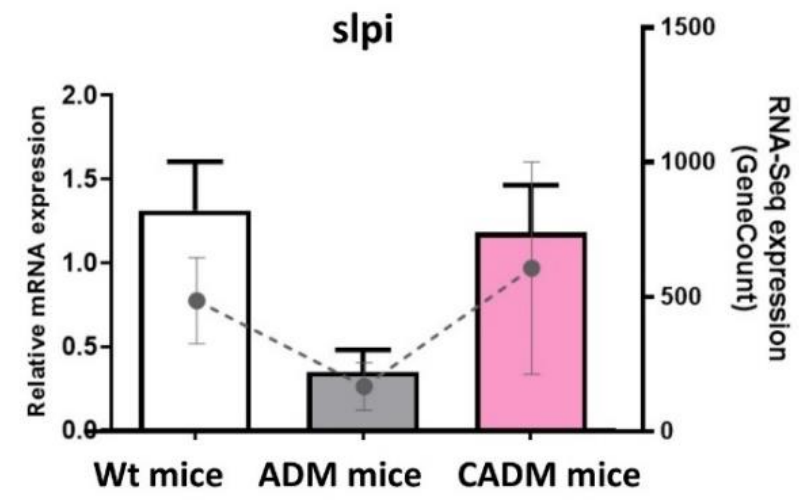

Ighv11-2

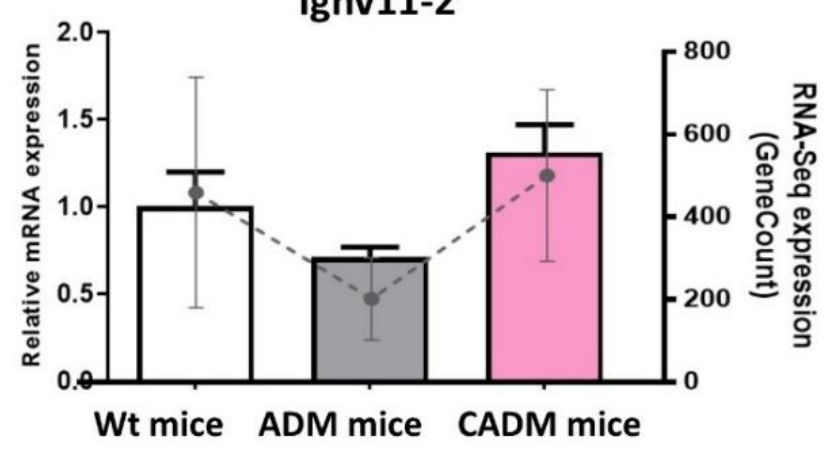

d630045ji12rik

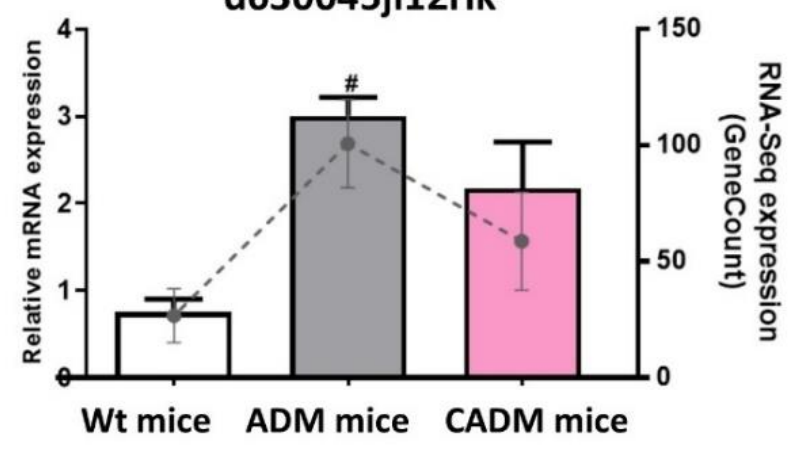

Igkv8-28

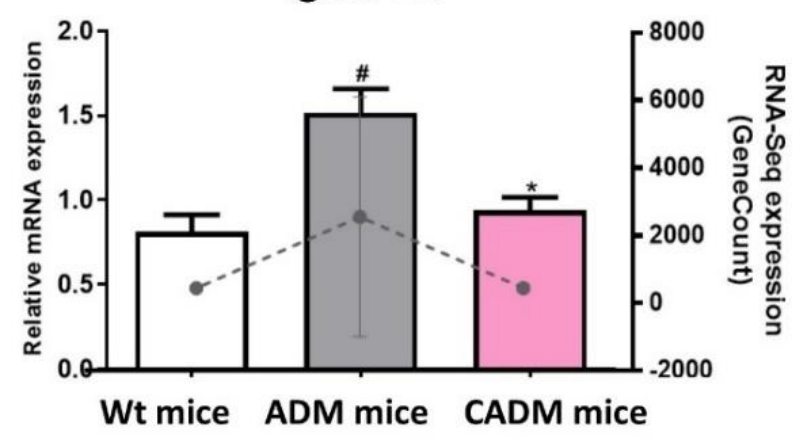

oas2

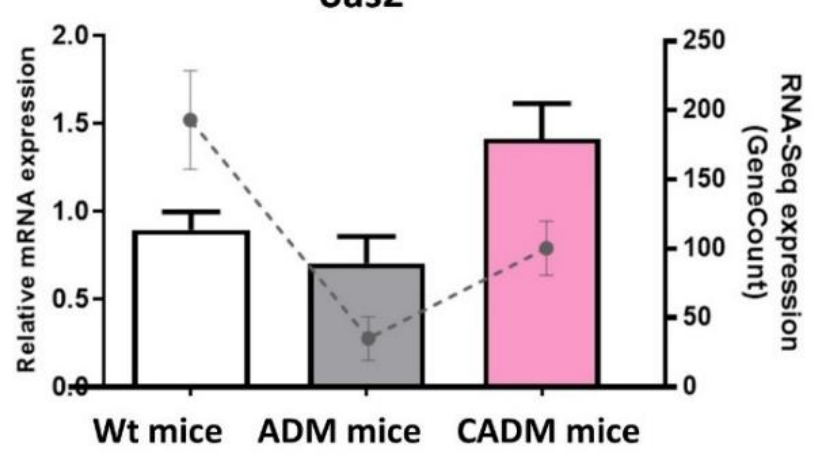

cd209e

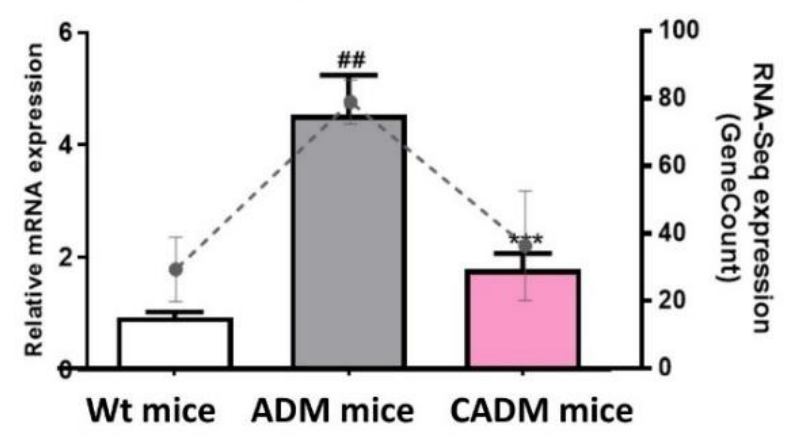

gm10260

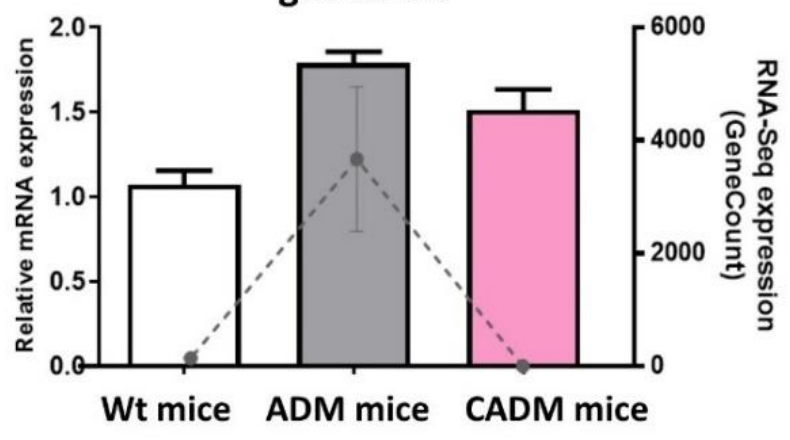

Bars are showing qRT-PCR relative expression of the gene in graph.

Dotted line is showing RNA-seq expression of the gene in the graph.

$\mathrm{X}$-axis: Groups studied in the study are plotted.

Figure 4. qRT-PCR expression of selected genes in all three groups plotted with RNA-Seq expression. \#p<0.05, \#\#p<0.01 vs. wild-type mice (Wt mice); ${ }^{*} p<0.05$ and ${ }^{* * *} p<0.001$ vs. ADM mice+C3G (CADM mice). 


\section{Discussion}

Comparative whole-transcriptome analysis of C3G-treated ADM mice was conducted to identify the genes and subsequently infer possible molecular mechanisms underlying the antioxidant and immunomodulatory properties of C3G observed in a number of studies $[7,10,14,15,20,27]$. Further analysis considering the importance of these properties in various diseases was conducted to explore the genes and the potential mechanism involved in the antioxidant and immune-modulation effects of C3G to develop it as a possible therapeutic not only for $\mathrm{AD}$, but also for other disease conditions. In an earlier study, C3G also alleviated the cognitive impairment in the same Alzheimer's mouse model [27]. Neuroinflammation in the brain might be associated with the immune response in the whole body [62]. Therefore, we wanted to focus on the antioxidant and immunomodulatory activities of C3G in the spleen of the APPswe/PS1dE9 mouse model of AD [63]. Spleen tissue has been used to investigate the immunomodulatory and antioxidant effects of phytochemicals in animal models [33,34]. The transcriptome of the spleen, one of the important organs of the immune system, was generated and comparatively analyzed among the Wt mice, ADM mice, and ADM mice+C3G (treated with $\mathrm{C} 3 \mathrm{G}$ ) groups. The transcriptomic sequences obtained from the samples derived from the different groups were assembled using a reference-based assembly method, the method of choice for an organism with a high-quality genome sequence available. The high percentage $(>95 \%)$ of good-quality reads (Table 1 ) and the high alignment rate $(>92 \%)$ of reads with the reference genome in all nine samples verified the high quality of the samples used in the study (Table 1). The unique transcriptomic resource of C3G-treated mice generated in the current study can also be used in future studies. Standard pipelines $[47,61]$ were used for the identification of gene expression and differential gene expression analysis in all the groups. Pathway enrichment analysis revealed that the pathways associated with the immune response such as inflammation-mediated chemokines and cytokines, the integrin pathway, gamma-aminobutyric acid (GABA) B receptor signaling, FAS signaling, and antioxidant activity such as the oxidative stress response (P00046) were enriched in DEGs upregulated in the ADM mice+C3G group (Table S4d). The genes that were up- or downregulated in both comparisons might be important in AD pathogenesis, with the ADM mice+C3G group as the treatment group compared with AM; the Wt mice represent a group of wild-type mice. Thus, the differences between both the Wt mice and the CADM mice compared with the ADM mice might be associated with AD pathology. Five genes (Slpi, Oas2, Gm15133, Ighv11-2, and Nnt) were found to be upregulated in both comparisons. Four (Slpi, Oas2, Ighv11-2, and Nnt) of these five genes are associated with the immune response [64-67]. The one remaining gene (Gm15133) has not been well-studied and is listed as a predicted gene. The involvement of most of these upregulated genes in the immune response/immune modulation and the association of two (Slpi and Nnt) of these genes with $\mathrm{AD}$ suggests the need to investigate all of these five genes in the future as candidate genes underlying the immunomodulatory mechanism in $\mathrm{AD}[68,69]$. Interestingly, Slpi and Nnt are known to contribute to antioxidant properties, as reported in the literature [70,71]. Similarly, four genes (Cd209e, D630045J12Rik, Gm10260, and Igkv8-28) were found to be downregulated in both comparative analyses. Of them, two (Cd209e and Igkv8-28) might be associated with the immune response [72,73]. The analysis of these important DEGs in both comparisons via RT-PCR revealed a similar pattern of expression as in the RNA-Seq experiment. These outcomes further support the reliability of the study and strongly suggest these genes as candidates for further investigation into their roles as target genes in C3G treatment. Furthermore, we propose that the upregulation of the six antioxidant genes in the C3G treatment group can be a major molecular mechanism providing antioxidant properties. Additionally, no antioxidant genes were found to be downregulated in the C3G-treated group. These results justify the current approach (Figure 3B), suggesting that the upregulation of antioxidant genes (S100a8, S100a9, Prdx2, Hp, Mpst, and Prx12a) may represent a new avenue for further exploration of the antioxidant mechanisms of C3G in different diseases. Additionally, these 
antioxidant genes are associated with immune responses, especially inflammation. Most of these genes (S100a8, S100a9, Prdx2, Hp, and Mpst) were also associated with AD in earlier studies [74-79]. Furthermore, the upregulation of 28 genes in the immune system database and 33 in the innate gene DBs could have directly contributed to the acquired and innate immunity in the ADM mice+C3G group, respectively. The upregulation of immunity, especially innate immunity, might be one of the critical mechanisms that support the immune-regulation effects of C3G and the subsequent impact on AD and other diseases [38]. The upregulation of antioxidant and immunity genes was found to be a possible mechanism creating the antioxidant and immune-modulatory properties of C3G treatment in the current study. Further studies are needed to explore the precise role of upregulated and common DEGs to optimize the therapeutic potential of $\mathrm{C} 3 \mathrm{G}$. Although a similar response from C3G treatment can be expected in different tissues, it may or may not be the same. Therefore, further studies using other tissues are recommended according to the disease and/or the condition under investigation. In addition, C3G-treated wild-type mice can be included in future studies for comparison with the ADM mice+C3G group, which may be helpful to better understand the therapeutic effects of $C 3 G$ and the subsequent impact on AD.

\section{Conclusions}

For the first time, a comparative transcriptome analysis of the spleen obtained from a C3G-treated mouse model of AD was conducted. Some DEGs important for immunity and antioxidant activity were found to be common in both comparisons, suggesting their pivotal roles in AD pathogenesis and the need for further in vitro and in vivo experiments. An upregulation of antioxidant and immuno-related genes was observed in the C3G-treated mice, which might be important antioxidant and immune modulation mechanisms in C3G therapy. These findings underscore the need to further explore these specific genes as therapeutic targets in $\mathrm{C} 3 \mathrm{G}$ treatment for $\mathrm{AD}$ and other important diseases such as cancer.

Supplementary Materials: The following materials are available online at https:/ /www.mdpi.com/ article/10.3390/antiox10091435/s1, Figure S1a: Graphical representation of preprocessing results; Figure S1b: Multidimensional scaling and t-SNE plot for all samples used in the study; Figure S2a: Bubble plot for GO annotation of 53 downregulated DEGs in a comparison between ADM mice vs. ADM mice+C3Ggroups; Figure S2b: Bubble plot for GO annotation of 904 down regulated DEGs in a comparison between ADM mice vs. Wt mice groups; Figure S2c: Bubble plot for Reactome annotation of 487 upregulated DEGs in a comparison between ADM mice vs. ADM mice+C3G groups; Figure S3a: Protein-protein interaction network between the DEGs identified in ADM mice vs. $\mathrm{Wt}$ mice comparison; Figure S3b. Protein-protein interaction network between the DEGs identified in ADM mice vs. ADM mice+C3G comparison; Table S1: Primer sequences used in RT-PCR experiment; Table S2a: Results of 444 DEGs (upregulated in Wt mice vs. ADM mice comparison) according to molecular function in panther enrichment analysis for molecular function; Table S2b: Results of 444 DEGs (upregulated in Wt mice vs. ADM mice comparison) according to cellular component in panther enrichment analysis for cellular components; Table S2c: Results of 444 DEGs (upregulated in Wt mice vs. ADM mice comparison) according to protein class in panther enrichment analysis for protein class; Table S2d: Results of 444 DEGs (upregulated in Wt mice vs. ADM mice comparison) according to pathways in panther enrichment analysis for pathways; Table S2e: Results of 444 DEGs (upregulated in $\mathrm{Wt}$ mice vs. ADM mice comparison) in Reactome pathway analysis; Table S2f: Results of 444 DEGs (upregulated in Wt mice vs. ADM mice comparison) according to biological function in panther enrichment analysis for biological function; Table S3a: Results of 904 DEGs (downregulated in Wt mice vs. ADM mice comparison) according to in panther enrichment analysis for molecular function; Table S3b: Results of 904 DEGs (downregulated in Wt mice vs. ADM mice comparison) in panther enrichment analysis for cellular components; Table S3c: Results of 904 DEGs (downregulated in Wt mice vs. ADM mice comparison) in panther enrichment analysis for protein class; Table S3d: Results of 904 DEGs (downregulated in Wt mice vs. ADM mice comparison) in panther enrichment analysis for pathways; Table S3e: Results of 904 DEGs (downregulated in Wt mice vs. ADM mice comparison) in Reactome pathway analysis; Table S3f: Results of 904 DEGs (downregulated in Wt mice vs. ADM mice comparison) in panther enrichment analysis for biological function; 
Table S4a: Results of 487 DEGs (upregulated in ADM mice+C3G vs. ADM mice comparison) in panther enrichment analysis for molecular function; Table S4b: Results of 487 DEGs (upregulated in ADM mice+C3G vs. ADM mice comparison) in panther enrichment analysis for cellular components; Table S4c: Results of 487 DEGs (upregulated in ADM mice+C3G vs. ADM mice comparison) in panther enrichment analysis for protein class; Table S4d: Results of 487 DEGs (upregulated in ADM mice+C3G vs. ADM mice comparison) in panther enrichment analysis for pathways; Table S4e: Results of 487 DEGs (upregulated in ADM mice+C3G vs. ADM mice comparison) Reactome pathway analysis; Table S4f: Results of 487 DEGs (upregulated in ADM mice+C3G vs. ADM mice comparison) in panther enrichment analysis for biological function; Table S5a: Results of 53 DEGs (downregulated in ADM mice+C3G vs. ADM mice comparison) according to molecular function in panther enrichment analysis for molecular function; Table S5b: Results of 53 DEGs (downregulated in ADM mice+C3G vs. ADM mice comparison) according to cellular component in panther enrichment analysis for cellular components; Table S5c: Results of 53 DEGs (downregulated in ADM mice+C3G vs. ADM mice comparison) according to protein class in panther enrichment analysis for protein class; Table S5d: Results of 53 DEGs (downregulated in ADM mice+C3G vs. ADM mice comparison) according to pathways in panther enrichment analysis for pathways; Table S5e: Results of 53 DEGs (downregulated in ADM mice+C3G vs. ADM mice comparison) in panther enrichment analysis for biological function; Table S6a: PPN1 Network stats of protein-protein interaction network from STRING; Table S6b: PPN2 Network stats of protein-protein interaction network from STRING.

Author Contributions: Investigation and data organization, V.J.; original draft preparation and visualization, M.P. and V.J.; conceptualization and supervision, H.-J.L. All authors have read and agreed to the published version of the manuscript.

Funding: This study was supported by the Cooperative Research Program of the Center for Companion Animal Research (Project No. PJ01476703), funded by the Rural Development Administration, Republic of Korea. It was also supported by GRRC program of Gyeonggi province (GRRC-Gachon2020 (B03)), funded by Development of Healthcare Contents based on AI.

Institutional Review Board Statement: The study was conducted in accordance with guidelines stipulated by the Ministry of Food and Drug Safety for the Care and Use of Laboratory Animals. It was approved by the Institutional Animal Care and Use Committee of the Eulji University School of Medicine (EUIACUC 20-13).

Informed Consent Statement: Not applicable.

Data Availability Statement: RNA-Seq data generated and utilized in the study is submitted to publically accessible NCBI repository (BioProject: PRJNA749157).

Acknowledgments: We would like to thank Yeonjae Angel Lee (Department of Neuroscience, Johns Hopkins University) for helping with grammar correction and proofreading the revision.

Conflicts of Interest: The authors have no conflict of interest to disclose.

\section{References}

1. Jia, Y.; Wu, C.; Kim, Y.-S.; Yang, S.O.; Kim, Y.; Kim, J.-S.; Jeong, M.-Y.; Lee, J.H.; Kim, B.; Lee, S. A dietary anthocyanin cyanidin3-O-glucoside binds to PPARs to regulate glucose metabolism and insulin sensitivity in mice. Commun. Biol. 2020, 3, 1-10. [CrossRef]

2. Li, W.; Chen, S.; Zhou, G.; Li, H.; Zhong, L.; Liu, S. Potential role of cyanidin 3-glucoside (C3G) in diabetic cardiomyopathy in diabetic rats: An in vivo approach. Saudi J. Biol. Sci. 2018, 25, 500-506. [CrossRef] [PubMed]

3. Qin, Y.; Zhai, Q.; Li, Y.; Cao, M.; Xu, Y.; Zhao, K.; Wang, T. Cyanidin-3-O-glucoside ameliorates diabetic nephropathy through regulation of glutathione pool. Biomed. Pharmacother. 2018, 103, 1223-1230. [CrossRef] [PubMed]

4. Lim, S.-M.; Lee, H.S.; Jung, J.I.; Kim, S.M.; Kim, N.Y.; Seo, T.S.; Bae, J.-S.; Kim, E.J. Cyanidin-3-O-galactoside-enriched Aronia melanocarpa extract attenuates weight gain and adipogenic pathways in high-fat diet-induced obese C57BL/6 mice. Nutrients 2019, 11, 1190. [CrossRef] [PubMed]

5. Aloud, B.M.; Raj, P.; McCallum, J.; Kirby, C.; Louis, X.L.; Jahan, F.; Yu, L.; Hiebert, B.; Duhamel, T.A.; Wigle, J.T. Cyanidin 3-O-glucoside prevents the development of maladaptive cardiac hypertrophy and diastolic heart dysfunction in 20-week-old spontaneously hypertensive rats. Food Funct. 2018, 9, 3466-3480. [CrossRef] [PubMed]

6. Liu, F.; Zhao, F.; Wang, W.; Sang, J.; Jia, L.; Li, L.; Lu, F. Cyanidin-3-O-glucoside inhibits A $\beta 40$ fibrillogenesis, disintegrates preformed fibrils, and reduces amyloid cytotoxicity. Food Funct. 2020, 11, 2573-2587. [CrossRef] 
7. Ma, B.; Wu, Y.; Chen, B.; Yao, Y.; Wang, Y.; Bai, H.; Li, C.; Yang, Y.; Chen, Y. Cyanidin-3-O- $\beta$-glucoside attenuates allergic airway inflammation by modulating the IL-4R $\alpha$-STAT6 signaling pathway in a murine asthma model. Int. Immunopharmacol. 2019, 69, 1-10. [CrossRef]

8. Wang, Y.; Zhang, Y.; Wang, X.; Liu, Y.; Xia, M. Supplementation with cyanidin-3-O- $\beta$-glucoside protects against hypercholesterolemia-mediated endothelial dysfunction and attenuates atherosclerosis in apolipoprotein E-deficient mice. J. Nutr. 2012, 142, 1033-1037. [CrossRef]

9. Amararathna, M.; Hoskin, D.W.; Rupasinghe, H. Cyanidin-3-O-Glucoside-Rich Haskap Berry Administration Suppresses Carcinogen-Induced Lung Tumorigenesis in A/JCr Mice. Molecules 2020, 25, 3823. [CrossRef]

10. Mazewski, C.; Kim, M.S.; de Mejia, E.G. Anthocyanins, delphinidin-3-O-glucoside and cyanidin-3-O-glucoside, inhibit immune checkpoints in human colorectal cancer cells in vitro and in silico. Sci. Rep. 2019, 9, 11560. [CrossRef]

11. Liu, M.; Du, Y.; Li, H.; Wang, L.; Ponikwicka-Tyszko, D.; Lebiedzinska, W.; Pilaszewicz-Puza, A.; Liu, H.; Zhou, L.; Fan, H. Cyanidin-3-o-glucoside pharmacologically inhibits tumorigenesis via estrogen receptor $\beta$ in melanoma mice. Front. Oncol. 2019, 9, 1110. [CrossRef]

12. Jongsomchai, K.; Leardkamolkarn, V.; Mahatheeranont, S. A rice bran phytochemical, cyanidin 3-glucoside, inhibits the progression of PC3 prostate cancer cell. Anat. Cell Biol. 2020, 53, 481. [CrossRef] [PubMed]

13. Chen, D.; Yuan, M.; Ye, Q.; Wang, X.; Xu, J.; Shi, G.; Hu, Z. Cyanidin-3-O-glucoside inhibits epithelial-to-mesenchymal transition, and migration and invasion of breast cancer cells by upregulating KLF4. Food Nutr. Res. 2020, 64. [CrossRef] [PubMed]

14. Sun, Y.; Li, L. Cyanidin-3-glucoside inhibits inflammatory activities in human fibroblast-like synoviocytes and in mice with collagen-induced arthritis. Clin. Exp. Pharmacol. Physiol. 2018, 45, 1038-1045. [CrossRef] [PubMed]

15. Sukprasansap, M.; Chanvorachote, P.; Tencomnao, T. Cyanidin-3-glucoside activates Nrf2-antioxidant response element and protects against glutamate-induced oxidative and endoplasmic reticulum stress in HT22 hippocampal neuronal cells. BMC Complementary Med. Ther. 2020, 20, 1-12. [CrossRef]

16. Ferrari, D.; Cimino, F.; Fratantonio, D.; Molonia, M.S.; Bashllari, R.; Busà, R.; Saija, A.; Speciale, A. Cyanidin-3-O-glucoside modulates the in vitro inflammatory crosstalk between intestinal epithelial and endothelial cells. Mediat. Inflamm. 2017, 2017. [CrossRef]

17. Shin, H.-Y.; Kim, J.; Lee, S.; Park, M.S.; Park, S.; Huh, S. Cause-of-death statistics in 2018 in the Republic of Korea. J. Korean Med Assoc./Taehan Uisa Hyophoe Chi 2020, 63, 286-297.

18. 2020 Alzheimer's disease facts and figures. Alzheimer's Dement. 2020, 16, 391-460. [CrossRef]

19. 2021 Alzheimer's disease facts and figures. Alzheimer's Dement. 2021, 17, 327-406. [CrossRef]

20. Yang, J.S.; Perveen, S.; Ha, T.J.; Kim, S.Y.; Yoon, S.H. Cyanidin-3-glucoside inhibits glutamate-induced $\mathrm{Zn}^{2+}$ signaling and neuronal cell death in cultured rat hippocampal neurons by inhibiting $\mathrm{Ca}^{2+}$-induced mitochondrial depolarization and formation of reactive oxygen species. Brain Res. 2015, 1606, 9-20. [CrossRef]

21. Bhuiyan, M.I.H.; Kim, H.-B.; Kim, S.Y.; Cho, K.-O. The neuroprotective potential of cyanidin-3-glucoside fraction extracted from mulberry following oxygen-glucose deprivation. Korean J. Physiol. Pharmacol. Off. J. Korean Physiol. Soc. Korean Soc. Pharmacol. 2011, 15, 353. [CrossRef]

22. Kang, T.H.; Hur, J.Y.; Kim, H.B.; Ryu, J.H.; Kim, S.Y. Neuroprotective effects of the cyanidin-3-O- $\beta$-d-glucopyranoside isolated from mulberry fruit against cerebral ischemia. Neurosci. Lett. 2006, 391, 122-126. [CrossRef]

23. Ke, Z.; Liu, Y.; Wang, X.; Fan, Z.; Chen, G.; Xu, M.; Bower, K.A.; Frank, J.A.; Ou, X.; Shi, X. Cyanidin-3-glucoside ameliorates ethanol neurotoxicity in the developing brain. J. Neurosci. Res. 2011, 89, 1676-1684. [CrossRef] [PubMed]

24. Yang, J.S.; Jeon, S.; Yoon, K.D.; Yoon, S.H. Cyanidin-3-glucoside inhibits amyloid $\beta 25-35$-induced neuronal cell death in cultured rat hippocampal neurons. Korean J. Physiol. Pharmacol. Off. J. Korean Physiol. Soc. Korean Soc. Pharmacol. 2018, 22, 689. [CrossRef]

25. Tarozzi, A.; Merlicco, A.; Morroni, F.; Franco, F.; Cantelli-Forti, G.; Teti, G.; Falconi, M.; Hrelia, P. Cyanidin 3-O-glucopyranoside protects and rescues SH-SY5Y cells against amyloid-beta peptide-induced toxicity. Neuroreport 2008, 19, 1483-1486. [CrossRef] [PubMed]

26. Tarozzi, A.; Morroni, F.; Merlicco, A.; Bolondi, C.; Teti, G.; Falconi, M.; Cantelli-Forti, G.; Hrelia, P. Neuroprotective effects of cyanidin 3-O-glucopyranoside on amyloid beta (25-35) oligomer-induced toxicity. Neurosci. Lett. 2010, 473, 72-76. [CrossRef]

27. Song, N.; Zhang, L.; Chen, W.; Zhu, H.; Deng, W.; Han, Y.; Guo, J.; Qin, C. Cyanidin 3-O- $\beta$-glucopyranoside activates peroxisome proliferator-activated receptor- $\gamma$ and alleviates cognitive impairment in the APPswe/PS1 $\triangle \mathrm{E} 9$ mouse model. Biochim. Biophys. Acta (BBA)-Mol. Basis Dis. 2016, 1862, 1786-1800. [CrossRef] [PubMed]

28. Qin, L.; Zhang, J.; Qin, M. Protective effect of cyanidin 3-O-glucoside on beta-amyloid peptide-induced cognitive impairment in rats. Neurosci. Lett. 2013, 534, 285-288. [PubMed]

29. Frost, G.R.; Jonas, L.A.; Li, Y.-M. Friend, foe or both? Immune activity in Alzheimer's disease. Front. Aging Neurosci. 2019, 11, 337. [CrossRef]

30. Lewis, S.M.; Williams, A.; Eisenbarth, S.C. Structure and function of the immune system in the spleen. Sci. Immunol. 2019, 4, eaau6085. [CrossRef]

31. Gu, X.; Ma, Z.; Fang, J.; Cai, D.; Zuo, Z.; Liang, S.; Cui, H.; Deng, J.; Ma, X.; Ren, Z. Obesity enhances antioxidant capacity and reduces cytokine levels of the spleen in mice to resist splenic injury challenged by Escherichia coli. J. Immunol. Res. 2020, 2020, 5948256-13. [CrossRef] 
32. Sun, Y.; Li, Y.; An, J.; Liu, Z.; Chen, Q. Antioxidative and inflammatory responses in spleen and head kidney of yellow catfish (pelteobagrus fulvidraco) induced by waterborne cadmium exposure. Turk. J. Fish. Aquat. Sci. 2019, 20, 87-96.

33. Zhang, M.; Luo, J.; Zhang, C.; Cao, H.; Xia, B.; Hu, G. Alterations in antioxidant function and cell apoptosis in duck spleen exposed to molybdenum and/or cadmium. J. Vet. Sci. 2017, 18, 193. [CrossRef]

34. Omar, H.E.-D.M.; Eldien, H.M.S.; Badary, M.S.; Al-Khatib, B.Y.; AbdElgaffar, S.K. The immunomodulating and antioxidant activity of fucoidan on the splenic tissue of rats treated with cyclosporine A. J. Basic Appl. Zool. 2013, 66, 243-254. [CrossRef]

35. Chawla, A.; Stobdan, T.; Srivastava, R.B.; Jaiswal, V.; Chauhan, R.S.; Kant, A. Sex-biased temporal gene expression in male and female floral buds of seabuckthorn (Hippophae rhamnoides). PLoS ONE 2015, 10, e0124890. [CrossRef] [PubMed]

36. Guleria, V.; Jaiswal, V. Comparative transcriptome analysis of different stages of Plasmodium falciparum to explore vaccine and drug candidates. Genomics 2020, 112, 796-804. [CrossRef] [PubMed]

37. Jaiswal, V.; Chauhan, R.S.; Rout, C. Common antigens prediction in bacterial bioweapons: A perspective for vaccine design. Infect. Genet. Evol. 2014, 21, 315-319. [CrossRef]

38. Jaiswal, V.; Cho, Y.-I.; Lee, H.-J. Preliminary Study to Explore the Immune-Enhancement Mechanism of Platycodon grandiflorus Extract through Comparative Transcriptome Analysis. Appl. Sci. 2021, 11, 226. [CrossRef]

39. Sood, A.; Jaiswal, V.; Chanumolu, S.K.; Malhotra, N.; Pal, T.; Chauhan, R.S. Mining whole genomes and transcriptomes of Jatropha (Jatropha curcas) and Castor bean (Ricinus communis) for NBS-LRR genes and defense response associated transcription factors. Mol. Biol. Rep. 2014, 41, 7683-7695. [CrossRef]

40. Vishambra, D.; Srivastava, M.; Dev, K.; Jaiswal, V. Subcellular localization based comparative study on radioresistant bacteria: A novel approach to mine proteins involve in radioresistance. Comput. Biol. Chem. 2017, 69, 1-9. [CrossRef]

41. Sudhagar, A.; Kumar, G.; El-Matbouli, M. Transcriptome analysis based on RNA-Seq in understanding pathogenic mechanisms of diseases and the immune system of fish: A comprehensive review. Int. J. Mol. Sci. 2018, 19, 245. [CrossRef]

42. Jankowsky, J.L.; Fadale, D.J.; Anderson, J.; Xu, G.M.; Gonzales, V.; Jenkins, N.A.; Copeland, N.G.; Lee, M.K.; Younkin, L.H.; Wagner, S.L. Mutant presenilins specifically elevate the levels of the 42 residue $\beta$-amyloid peptide in vivo: Evidence for augmentation of a 42-specific $\gamma$ secretase. Hum. Mol. Genet. 2004, 13, 159-170. [CrossRef]

43. Wang, D.; Xia, M.; Yan, X.; Li, D.; Wang, L.; Xu, Y.; Jin, T.; Ling, W. Gut microbiota metabolism of anthocyanin promotes reverse cholesterol transport in mice via repressing miRNA-10b. Circ. Res. 2012, 111, 967-981. [CrossRef]

44. Chen, S.; Huang, T.; Zhou, Y.; Han, Y.; Xu, M.; Gu, J. AfterQC: Automatic filtering, trimming, error removing and quality control for fastq data. BMC Bioinform. 2017, 18, 91-100. [CrossRef]

45. Kim, D.; Paggi, J.M.; Park, C.; Bennett, C.; Salzberg, S.L. Graph-based genome alignment and genotyping with HISAT2 and HISAT-genotype. Nat. Biotechnol. 2019, 37, 907-915. [CrossRef]

46. Li, H.; Handsaker, B.; Wysoker, A.; Fennell, T.; Ruan, J.; Homer, N.; Marth, G.; Abecasis, G.; Durbin, R. The sequence alignment/map format and SAMtools. Bioinformatics 2009, 25, 2078-2079. [CrossRef] [PubMed]

47. Pertea, M.; Kim, D.; Pertea, G.M.; Leek, J.T.; Salzberg, S.L. Transcript-level expression analysis of RNA-seq experiments with HISAT, StringTie and Ballgown. Nat. Protoc. 2016, 11, 1650. [CrossRef] [PubMed]

48. Robinson, M.D.; McCarthy, D.J.; Smyth, G.K. edgeR: A Bioconductor package for differential expression analysis of digital gene expression data. Bioinformatics 2010, 26, 139-140. [CrossRef]

49. Love, M.I.; Huber, W.; Anders, S. Moderated estimation of fold change and dispersion for RNA-seq data with DESeq2. Genome Biol. 2014, 15, 1-21. [CrossRef] [PubMed]

50. Mi, H.; Ebert, D.; Muruganujan, A.; Mills, C.; Albou, L.-P.; Mushayamaha, T.; Thomas, P.D. PANTHER version 16: A revised family classification, tree-based classification tool, enhancer regions and extensive API. Nucleic Acids Res. 2021, 49, D394-D403. [CrossRef] [PubMed]

51. Zhang, D.; Hu, Q.; Liu, X.; Zou, K.; Sarkodie, E.K.; Liu, X.; Gao, F. AllEnricher: A comprehensive gene set function enrichment tool for both model and non-model species. BMC Bioinform. 2020, 21, 1-6. [CrossRef]

52. Consortium, G.O. The gene ontology resource: 20 years and still GOing strong. Nucleic Acids Res. 2019, 47, D330-D338.

53. Fabregat, A.; Jupe, S.; Matthews, L.; Sidiropoulos, K.; Gillespie, M.; Garapati, P.; Haw, R.; Jassal, B.; Korninger, F.; May, B. The reactome pathway knowledgebase. Nucleic Acids Res. 2018, 46, D649-D655. [CrossRef]

54. Heberle, H.; Meirelles, G.V.; da Silva, F.R.; Telles, G.P.; Minghim, R. InteractiVenn: A web-based tool for the analysis of sets through Venn diagrams. BMC Bioinform. 2015, 16, 1-7. [CrossRef] [PubMed]

55. Feng, P.; Ding, H.; Lin, H.; Chen, W. AOD: The antioxidant protein database. Sci. Rep. 2017, 7, 7449. [CrossRef] [PubMed]

56. Raudvere, U.; Kolberg, L.; Kuzmin, I.; Arak, T.; Adler, P.; Peterson, H.; Vilo, J. g: Profiler: A web server for functional enrichment analysis and conversions of gene lists (2019 update). Nucleic Acids Res. 2019, 47, W191-W198. [CrossRef] [PubMed]

57. Breuer, K.; Foroushani, A.K.; Laird, M.R.; Chen, C.; Sribnaia, A.; Lo, R.; Winsor, G.L.; Hancock, R.E.; Brinkman, F.S.; Lynn, D.J. InnateDB: Systems biology of innate immunity and beyond-Recent updates and continuing curation. Nucleic Acids Res. 2013, 41, D1228-D1233. [CrossRef] [PubMed]

58. Szklarczyk, D.; Gable, A.L.; Nastou, K.C.; Lyon, D.; Kirsch, R.; Pyysalo, S.; Doncheva, N.T.; Legeay, M.; Fang, T.; Bork, P. The STRING database in 2021: Customizable protein-protein networks, and functional characterization of user-uploaded gene/measurement sets. Nucleic Acids Res. 2021, 49, D605-D612. [CrossRef] [PubMed]

59. Yates, A.D.; Achuthan, P.; Akanni, W.; Allen, J.; Allen, J.; Alvarez-Jarreta, J.; Amode, M.R.; Armean, I.M.; Azov, A.G.; Bennett, R. Ensembl 2020. Nucleic Acids Res. 2020, 48, D682-D688. [CrossRef] [PubMed] 
60. Van der Maaten, L.; Hinton, G. Visualizing data using t-SNE. J. Mach. Learn. Res. 2008, 9, 2579-2605.

61. Ge, S.X.; Son, E.W.; Yao, R. iDEP: An integrated web application for differential expression and pathway analysis of RNA-Seq data. BMC Bioinform. 2018, 19, 1-24. [CrossRef] [PubMed]

62. Netea, M.G.; Domínguez-Andrés, J.; Barreiro, L.B.; Chavakis, T.; Divangahi, M.; Fuchs, E.; Joosten, L.A.B.; van der Meer, J.W.M.; Mhlanga, M.M.; Mulder, W.J.M.; et al. Defining trained immunity and its role in health and disease. Nat. Rev. Immunol. 2020, 20, 375-388. [CrossRef] [PubMed]

63. Di Benedetto, G.; Burgaletto, C.; Carta, A.R.; Saccone, S.; Lempereur, L.; Mulas, G.; Loreto, C.; Bernardini, R.; Cantarella, G. Beneficial effects of curtailing immune susceptibility in an Alzheimer's disease model. J. Neuroinflamm. 2019, 16, 1-17. [CrossRef] [PubMed]

64. Sallenave, J.-M. Secretory leukocyte protease inhibitor and elafin/trappin-2: Versatile mucosal antimicrobials and regulators of immunity. Am. J. Respir. Cell Mol. Biol. 2010, 42, 635-643. [CrossRef]

65. Dar, A.A.; Pradhan, T.N.; Kulkarni, D.P.; Shah, S.U.; Rao, K.V.; Chaukar, D.A.; D'Cruz, A.K.; Chiplunkar, S.V. Extracellular 2' $5^{\prime}$-oligoadenylate synthetase 2 mediates T-cell receptor CD 3- $\zeta$ chain down-regulation via caspase-3 activation in oral cancer. Immunology 2016, 147, 251-264. [CrossRef]

66. Meffre, E.; Milili, M.; Blanco-Betancourt, C.; Antunes, H.; Nussenzweig, M.C.; Schiff, C. Immunoglobulin heavy chain expression shapes the B cell receptor repertoire in human B cell development. J. Clin. Investig. 2001, 108, 879-886. [CrossRef]

67. Ripoll, V.M.; Meadows, N.A.; Bangert, M.; Lee, A.W.; Kadioglu, A.; Cox, R.D. Nicotinamide nucleotide transhydrogenase (NNT) acts as a novel modulator of macrophage inflammatory responses. FASEB J. 2012, 26, 3550-3562. [CrossRef]

68. Ghidoni, R.; Flocco, R.; Paterlini, A.; Glionna, M.; Caruana, L.; Tonoli, E.; Binetti, G.; Benussi, L. Secretory leukocyte protease inhibitor protein regulates the penetrance of frontotemporal lobar degeneration in progranulin mutation carriers. J. Alzheimer's Dis. 2014, 38, 533-539. [CrossRef] [PubMed]

69. Ghosh, D.; Levault, K.R.; Brewer, G.J. Relative importance of redox buffers GSH and NAD (P) H in age-related neurodegeneration and Alzheimer disease-like mouse neurons. Aging Cell 2014, 13, 631-640. [CrossRef] [PubMed]

70. Doumas, S.; Kolokotronis, A.; Stefanopoulos, P. Anti-inflammatory and antimicrobial roles of secretory leukocyte protease inhibitor. Infect. Immun. 2005, 73, 1271-1274. [CrossRef]

71. Rao, K.S.; Shen, X.; Pardue, S.; Krzywanski, D.M. Nicotinamide nucleotide transhydrogenase (NNT) regulates mitochondrial ROS and endothelial dysfunction in response to angiotensin II. Redox Biol. 2020, 36, 101650. [CrossRef]

72. Schetters, S.T.; Kruijssen, L.J.; Crommentuijn, M.H.; Kalay, H.; Ochando, J.; Den Haan, J.M.; Garcia-Vallejo, J.J.; Van Kooyk, Y. Mouse DC-SIGN/CD209a as target for antigen delivery and adaptive immunity. Front. Immunol. 2018, 9, 990. [CrossRef]

73. Watson, C.T.; Glanville, J.; Marasco, W.A. The individual and population genetics of antibody immunity. Trends Immunol. 2017, 38, 459-470. [CrossRef]

74. Salzano, S.; Checconi, P.; Hanschmann, E.-M.; Lillig, C.H.; Bowler, L.D.; Chan, P.; Vaudry, D.; Mengozzi, M.; Coppo, L.; Sacre, S. Linkage of inflammation and oxidative stress via release of glutathionylated peroxiredoxin-2, which acts as a danger signal. Proc. Natl. Acad. Sci. USA 2014, 111, 12157-12162. [CrossRef]

75. Szeliga, M. Peroxiredoxins in Neurodegenerative Diseases. Antioxidants 2020, 9, 1203. [CrossRef]

76. Wang, S.; Song, R.; Wang, Z.; Jing, Z.; Wang, S.; Ma, J. S100A8/A9 in Inflammation. Front. Immunol. 2018, 9, 1298. [CrossRef] [PubMed]

77. Cristóvão, J.S.; Gomes, C.M. S100 Proteins in Alzheimer's disease. Front. Neurosci. 2019, 13, 463. [CrossRef] [PubMed]

78. Wang, X.; Liu, G.J.; Gao, Q.; Li, N.; Wang, R.t. C-type lectin-like receptor 2 and zonulin are associated with mild cognitive impairment and Alzheimer's disease. Acta Neurol. Scand. 2020, 141, 250-255. [CrossRef] [PubMed]

79. Tabassum, R.; Jeong, N.Y.; Jung, J. Therapeutic importance of hydrogen sulfide in age-associated neurodegenerative diseases. Neural Regen. Res. 2020, 15, 653. [PubMed] 